\title{
Evaluation of new flexible and integrative psychiatric treatment models in Germany- assessment and preliminary validation of specific program components
}

\author{
Jakob Johne ${ }^{1^{*}+}$, Sebastian von Peter ${ }^{2 \dagger}$, Julian Schwarz ${ }^{2}$, Jürgen Timm ${ }^{3}$, Martin Heinze ${ }^{2}$ and Yuriy lgnatyev ${ }^{2}$
}

\begin{abstract}
Background: Flexible and integrative treatment (FIT) models are rather novel in German mental health care. This study aimed at identifying and evaluating empirically based, practicable, and quantifiable program components that describe the specific treatment structures and processes of German FIT models.

Methods: A multi-step, iterative research process, based on Grounded Theory Methodology (GTM), was used to identify and operationalise components. A complex algorithm and expert-interviews were applied to quantify the relative weight of each component and to develop a sum score. Face and content validity were examined and internal consistency was tested by Cronbach's a coefficient.

Results: Ten of eleven FIT components could be operationalised, quantified and united in the total score. All operationalised components showed sufficient face and content validity and eight components had a good reliability.

Conclusions: The components are a first step in the process of operationally defining German FIT models. They considerably overlap with various critical ingredients of international FIT models and may serve as a theoretical basis for constructing fidelity tools and research guides to enable process and outcome evaluation of German FIT models.
\end{abstract}

Keywords: Flexible, Integrative care, Mental health, Health services research, Regional budget

\section{Background}

Flexible and integrative treatment models (shortcut $=$ FIT-models) provided by multi-professional teams (e.g. Assertive Community Treatment (ACT), Home Treatment (HT), Crisis Resolution Teams (CRT) etc.) are widely perceived to be fundamental for adequate mental health care [1]. Accordingly, critical ingredients, evaluation criteria, and fidelity scales have been developed over the past 20 years, among other the Index of Fidelity for ACT (IF-ACT), Dartmouth Assertive Community Treatment Scale (DACTS), Tool for Measurement of

\footnotetext{
* Correspondence: jakob_johne@yahoo.de

† Jakob Johne and Sebastian von Peter contributed equally to this work. ${ }^{1}$ Department of Psychiatry and Psychotherapy, Charité University Medicine Berlin, Charitéplatz 1, 10117 Berlin, Germany

Full list of author information is available at the end of the article
}

ACT (TMACT), Individual Placement and Support Fidelity Scale (IPS25), Core Crisis Resolution Team fidelity scale (Core CRT fidelity scale) [2-8]. Further, a wide array of positive outcomes has been described: reduced costs, lesser rates of hospitalisation, lesser dropout rates, increased housing stability and client and family satisfaction were found to be evident for various community-based treatment models $[1,2,9]$.

Despite this evidence, patients with severe mental illness in Germany mostly receive separated in- and outpatient care, with a considerable proportion of inpatient treatment [10]. Further, the German system is characterized by a rather flawed integration of in-patient-services with out-patient and a broad spectrum of rather different psychosocial institutions [10, 11]. Usually, the German

(c) The Author(s). 2018 Open Access This article is distributed under the terms of the Creative Commons Attribution 4.0 International License (http://creativecommons.org/licenses/by/4.0/), which permits unrestricted use, distribution, and reproduction in any medium, provided you give appropriate credit to the original author(s) and the source, provide a link to the Creative Commons license, and indicate if changes were made. The Creative Commons Public Domain Dedication waiver (http://creativecommons.org/publicdomain/zero/1.0/) applies to the data made available in this article, unless otherwise stated. 
system is described to be fragmented [10]. One further striking feature is that outreach services are underdeveloped [12].

To improve this situation, a law has been introduced recently (year 2013, \$64b Book V German Social Law) that allows for new forms of psychiatric flexible and integrative treatment models (shortcut $=$ FIT64b). Contrasting to most international FIT models, and due to local contingencies [13], FIT64b services are offered by hospital-based teams to patients with both acute and chronic conditions (s. Fig. 1). Service providers receive a total budget for all forms of inpatient and hospital-based outpatient care (capitation principle $[14,15])$. This budget must cover all expenses, yet, leaving sufficient space for adapting treatments to the needs of a region or patient.

Meanwhile, a total of 20 FIT projects can be found in various parts of Germany. They differ considerably with regard to lengths of services, contextual settings, treatment structures, and processes, depending on historical contingencies and local conditions [16]. At the same time, they all seek to offer continuous, flexible, and integrative forms of care instead of rather brief and rigid sets of mainly inpatient treatment.

Scientific interest and legal directives require careful evaluation of this development. Quantitative data drawn from clinical account data bases are available, but they are not sufficient to evaluate the different FIT processes, outcomes, and evaluation of specific FIT aspects by patients and staff. Moreover, changes following the implementation of FIT models can be difficult to detect, as they are primarily of a budgetary nature. Thus, a theoretical program model had to be developed, delineating program components and integrating the structural and process variations of FIT projects.

The study, EvaMod64b (Evaluation of Models according to SGB $\$ 64 \mathrm{~b}$ ), was planned to overcome this gap. The results of the main study will be reported elsewhere (von Peter, Ignatyev et al.: Evaluation of flexible and integrative treatment models in Germany - a mixed method, patient and staff-oriented, explorative study. (in progress)). The aim of this paper was to identify and evaluate an empirically based, practicable, quantifiable, and theoretically sound set of program components that describe the specific treatment structures and processes of German FIT models.

\section{Methods}

\section{Setting and sampling}

This study was approved by the Ethics Committee of Medical Chamber Brandenburg (2016, No. S 7 (a)). All of the 15 hospitals with FIT64b models in 2015 where asked to participate in our study, out of which 12 Departments agreed (Itzehoe, Heide, Rendsburg, Lüneburg, Nordhausen (adult and child/ adolescent psychiatry), Glauchau, Riedstadt (adult and child/adolescent), Berlin-Kreuzberg, Berlin-Neukölln, and Rüdersdorf. The start of FIT64b models varied from January 2013 to January 2016. Seven departments had a prehistory of FIT in the frame work of another social regulation. The examined hospitals are both private (four departments) and public or non-profit (eight departments), and providing care for a regional population of 85,000 up to 425,000 people. Further, some FIT64b models signed contracts with only one or two insurance companies (four departments), other are under contract with all of them (four departments), meaning that in the

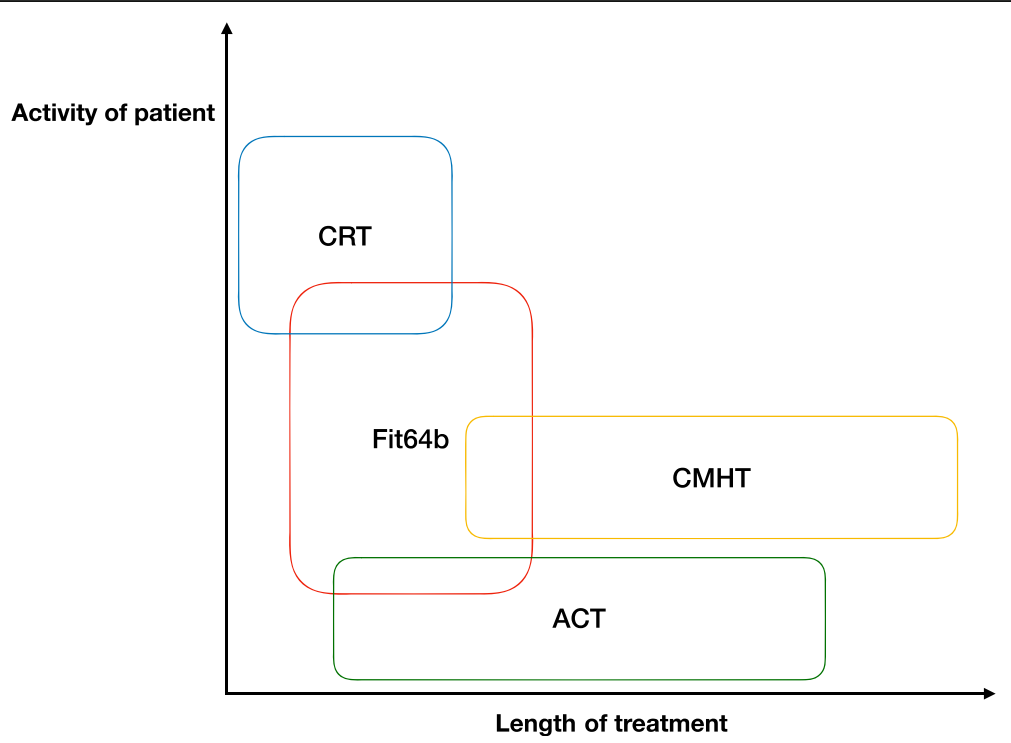

Fig. 1 Comparison of FIT models with international models. FIT64b models treat both chronic and acute patients usually for a longer time than CRT models and a shorter duration compared to ACT. 
former, not all patients received the FIT64b specific treatment procedures.

\section{Assessment of specific program components}

The assessment phase included five steps: 1) identification of program components; 2) operationalising program components; 3) quantification of component items; 4) rating of component items; and 5) weighting of components and component items (s. Fig. 2).

\section{Identification of program components}

As shown in the introduction, FIT64b models are complex interventions that contain multiple, and interacting, treatment components [17]. Secondly, FIT64b models vary widely, regarding structures and processes. Thirdly, changes following the implementation of FIT64b models can be difficult to detect, as they are primarily of a budgetary nature. Thus, a theoretical program model had to be developed, delineating program components and integrating the structural and process variations of FIT64b projects.

To identify the program components of FIT64b models, data collection was biphasic, occurring in September and October 2015, first in FIT64b projects Departments 1-6, then, after analysing data, in Departments 7-12. Focus groups [18] and expert interviews [19] of staff, patients, and family members were conducted by two authors (SvP, YI) to assess experiences with FIT64b models. The complete research guide cannot be displayed here due to reasons of space, but questions were asked on structural and processual features of FIT64b models, on caused changes in everyday routines and practices, and on perceived benefits and disadvantages.

A total of 14 focus groups and 12 expert interviews across all 9 FIT64b projects were conducted. In total, 24 employees, 16 patients, and four family members were included. Two-thirds of the employees were in management positions, three-quarters were daily workers in FIT64b projects, and three employees worked as controllers. Two-thirds of patients and family members were experienced with standard health care and, thus, were able to compare FIT and conventional psychiatric treatment systems.

Generally, GTM is used for pursuing rule-based and systematic processes of developing explanatory theories [20]. Such kinds of iterative alternations between data collection, analysis, and interpretation were also used to develop the contents of other FIT program components. Data analysis was intermittent. A constant iterative process of data collection and interpretation was performed until data was saturated [21]. Through this process, and over the course of the investigation, a set of recurring FIT64b program components was developed.

\section{Operationalising program components}

Using the iterative process, according to the GTM, the developed program components were operationalised. For each component, relevant structural and processual criteria were explored and discussed during the above-mentioned expert interviews and focus groups. Component items were constructed that address the main structural and processual changes that have to precede or follow the implementation of FIT64b models.

\section{Quantification of component items}

The first step of transforming the qualitatively defined and operationalised components to quantifiable items was to quantify each component item with a single value depending on the respective possibilities of answers $(0=$ not implemented, $1=$ partly implemented, 2 = fully implemented). In some cases, percentage ratios

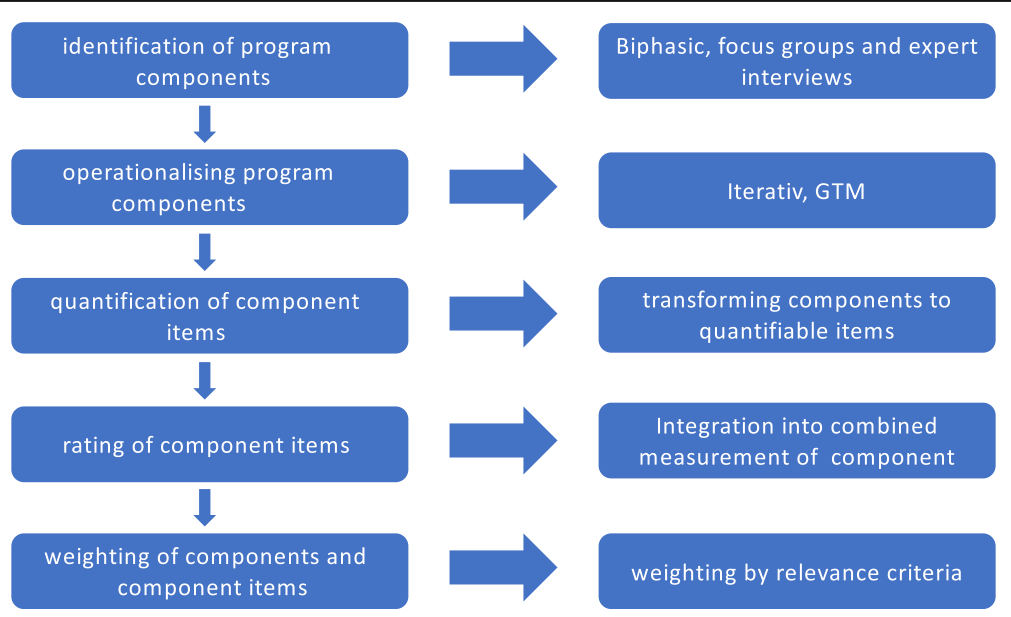

Fig. 2 Assessment phases of specific program components 
of implementation were used. Single items of components I, II, IV, VI, and IX are themselves quantitative as they ask for a count.

Starting quantification was compared with qualitative insights resulting from focus groups and expert interviews. Preliminary quantitative data from a first feasibility data collection in one clinic was integrated. Both resulted in an adjusted quantification using means of some item values (III a, b, c, V a, b and VII a, b, c). A specific problem evolved from the pair $a, b$, where $b$ is upgrading $a$. In these cases, they were integrated in one item quantified by the sum. Two items (IX a, b) were eliminated as they seemed to be not specific for the theme of the component.

\section{Rating of component items}

After development of item quantification, the question arose how to integrate the respective item quantification into a quantification of each component as a whole. The aim of this research step was to integrate the quantified items into a combined measurement of each FIT64b component.

A first attempt to use simple sums of item scores was rejected as the qualitative data showed great differences with respect to the importance between the single items. Instead, ratings of item relevance and relevance weighted sums of items for component, as well as combined components, were introduced.

Rating of the components was done by conducting expert interviews. Eleven academics from examined hospitals who actively dealt with FIT64b were questioned about the importance of the individual component items for quality of life of patients affected by the item. They were asked about the relevance within one year and within three years, and they were asked to state their certainty about the answers given. The answers should be given by scores of one (no impact) to five (strong impact), respectively, and by score one (totally uncertain) to five (totally certain).

\section{Weighting of component items and whole components}

In order to introduce a weighting of both components and component items by relevance criteria, an algorithm for this weighting process had to be developed. The algorithm, to transform item scores into component scores and a total score of FIT64b compliance, was based on the weighting resulting from expert assessments. In a first step, weighting of item scores affiliated with the component was used to produce component scores for each participating department. In the second step, weights for components were calculated in order to create a total score measuring the FIT64b compliance of the departments in general. In a third step, these component weights were applied to the department component scores produced in step one.

The algorithm used was developed as follows: Let Fij be the score given by clinic $j$ assessing the realisation of item $i$. The weighted sum of items for a component $k$ and clinic $j$ may be written as Mjk = sum(pik * Fij), where sum is calculated over all items i contained in component $\mathrm{k}$ and sum(pik) $=1$ for each $k$. The factors, pik, are derived from the expert votes as follows: let $\mathrm{Ai}$ be the mean of expert relevance ratings for item i (mean over all expert ratings for one year as well as three years). Let S1i and S3i be the mean scores of certainty assessment over all experts. As this measurement of uncertainty is subjective, we combined it with a more objective score D1i, respectively, D3i defined by the inverse standard deviation of expert assessments for item $\mathrm{i}$. By this we got combined certainty assessments $\mathrm{C} 1 \mathrm{i}$ $=\mathrm{f} * \mathrm{~S} 1 \mathrm{i}+\mathrm{D} 1 \mathrm{i}, \mathrm{C} 3 \mathrm{i}=\mathrm{f} * \mathrm{~S} 1 \mathrm{i}+\mathrm{D} 1 \mathrm{i}$, and $\mathrm{Ci}=\operatorname{mean}(\mathrm{C} 1 \mathrm{i}, \mathrm{C} 3 \mathrm{i})$. The factor $\mathrm{f}$ is used to balance the terms in the sum. We used $f=2.5$. The product of certainty and mean assessment $\mathrm{gi}=\mathrm{Ai} * \mathrm{Ci}$, yields the wanted weighting factor pik = gi / $\mathrm{Gk}$, where $\mathrm{Gk}=$ sum(all gi belonging to $\mathrm{k}$ ). In order to get an integrated measure for FIT compliance, we calculated a weighted sum of the resulting component values, Mjk, for clinic $k$. This is simply done by using the same weight factors as above, i.e. $\mathrm{MTj}=\operatorname{sum}(\mathrm{pk} * \mathrm{Mjk})$, where $\mathrm{k}=1, . ., 11$, and $\mathrm{pk}=\mathrm{Gk} / \mathrm{G}$ with $\mathrm{G}=\operatorname{sum}(\mathrm{Gk})$. Greater importance was given to components with weight of $10 \%$ or more regarding to total score.

\section{Testing internal consistency and content validity}

The validity phase included examining the face and content validity of FIT64b program components, as well as their internal consistence.

To test face validity, all program components were continuously discussed with staff and patients of FIT64b models during data collection. Further, a steering committee was established, consisting of the research team and of FIT64b project staffs, spanning all occupational groups, as well as of two representatives of patients and family members. This committee critically discussed and re-evaluated the components' validity and practicability before initiating the main study.

To examine the content validity of program components, the content validity ratio CVR [22] was calculated for each item based on the expert interviews with mean CVRs for each component and overall mean. The formula $\mathrm{CVR}=(\mathrm{Ne}-\mathrm{N} 2) / \mathrm{N} 2$ was used on the item level where Ne is the number of experts votes "essential" while $\mathrm{N}$ is the number of experts and $N 2=N / 2$. In a first step the raw items presented to the experts were examined in this way. As the scores ranged from 1 to 5 (no impact to strong impact) a score of at least 3 was interpreted as essential in the sense of this CVR analysis. In a second step the effect of our weighting approach was checked by the same procedure 
for the weighted items, $\mathrm{Gi}=\mathrm{Si}$ *Ai (see above), calculated separately for each expert and item. The Gi where defined to indicate essential scores if they were greater than the value, resulting by the same border of 3 for assessments and individual certainty together with a standard deviation smaller than that of an equal distribution.

To test the internal consistency of components, the estimation of Cronbach's $\alpha$ internal reliability coefficient was performed. The testing of reliability was carried out on the item component as well as component's weighted sum score levels. In a first step, the reliability of the base for the weighting algorithm was evaluated by testing agreement between experts assessing the relevance of each item of the components and their own estimate about the certainty of this assessment for a one year and a three-year time interval. A total of four sets (assessments and certainty for one and three years), regarding the 33 component items assessed by 10 experts, was tested by Cronbach's alpha [23].

In a second step, the reliability of the whole instrument, i.e. the weighting algorithm, was evaluated by constructing new weights by the same formal algorithm, not using the mean of the expert votes but applying the algorithm in a different way for each expert separately based on their individual assessments. This procedure yielded 10 different FIT64b measurements on the component level (10 components), as well as on the level of weighted sum of components, which were applied to the answers of the 12 departments involved in the study as a test data set. A Cronbach's $\alpha$ between 0.6 and 0.7 is considered an acceptable value. A value between 0.7 and 0.9 is a good value, and a value of 0.9 or higher indicates excellent reliability [24].

\section{Results}

\section{Program components}

The complex, multi-step, and iterative research process based on GTM resulted into 11 components of FIT64b programs, addressing the main areas of change from conventional to FIT64b oriented psychiatric treatment.

For reasons of space, each step of development on the basis of citations cannot be displayed here. Open coding in the Departments 1-6 resulted into program components I, II, IV, V, VI, and VII (see Table 1).

Following data collection in Departments 1-6, data were analysed with respect to these six initial components. They were further validated during the second phase of data collection in Departments 7-12. In addition, four components (III, VIII, IX, and XI, see Table 1) were added.

Data from both phases of data collection were analysed. When presented to the steering committee, the specific value of component V and IX were extensively debated, but finally accepted; as both components occur widely in non-FIT64b models. An additional component was suggested, component $\mathrm{X}$, as FIT64b models in
Germany also attempt to transcend hospital and other care models, and due to the fact that this component has also been described to be critical for flexible and integrative care models.

\section{Operationalisation}

Operationalised items are shown in Table 1. Due to reasons of space, only the most important changes during their course of development, and following their continuous validation during data collection and evaluation within the steering committee, are described here: Operationalisation of component I and partially of component VI was questioned, as it was unclear if it was a mediator or outcome itself. A patient-related operationalisation for component II could not be found; thus, the current ones refer to institutional changes. The remoteness of outpatient clinics largely prevents flexibilisation of treatments and, thus, was included in operationalising component III. The split between both the space- and team-related operationalisations of component VIII created a lack of unity during analyses. And finally, component II and IX were conceptually strongly related, thus mainly differing due to their calibration.

\section{Quantification}

Item answer scores, quantifying the operationalised components, were collected from the 12 study departments (Table 2). The values of these scores ranged from 0 to 12 with a mean of 1.17 and standard deviation of 1.55. Data for component I and in part for component VI were not included (see component I and VI problems in section "Operationalisation"). In some cases (component III, V, and VII), answers (3, 2 and 3 answers respectively) were combined to one item score. The only item of component VI was scored by " 1 " because of lack of variation in all departments.

\section{Rating}

Return rate of questionnaires was high (90.9\%). Experts expected increasing effects of FIT64b models on the long run with an average expectation of 3.64 for one year and 3.89 for three years. Small variations in ratings could be detected with a standard deviation of 0.398 and 0.382 (Table 3).

\section{Weighting}

Whereas components II, III, IV, VII, VIII, X, and XI achieved relative weight of $10 \%$ or more regarding to total score, components V, VI, and IX were of smaller importance (Table 3.)

The resulting total scores for each department are presented in Fig. 3 as an example of this measurement, illustrating the different FIT64b status of the involved departments. The values range from 0.63 to 1.73 , with mean of 1.15 and standard deviation of 0.33 . 
Table 1 Operationalization of FIT components

\begin{tabular}{|c|c|c|c|}
\hline No. & Component & Operationalisation & Assessment \\
\hline । & $\begin{array}{l}\text { Shifting in- to outpatient setting } \\
\text { Shift of treatment from } I^{1} \text { towards } D^{2} \text { and/or } O^{3}\end{array}$ & - Number of outpatient SoF$F^{4}$ total number SoF $F^{4}$ during $\mathrm{EP}^{5}$ & \\
\hline \multirow[t]{2}{*}{$\|$} & \multirow[t]{2}{*}{$\begin{array}{l}\text { Flexible care management across settings } \\
\text { Unproblematic shift of SoF } \text { (prompt, little } \\
\text { bureaucracy }\end{array}$} & $\begin{array}{l}\text { - Number of } \mathrm{CoT}^{6} \text { using all three } \mathrm{SoF}^{4} \text { during } \mathrm{EP}^{5} / \text { total number } \mathrm{CoT}^{6} \\
\text { - Treatment } \mathrm{D}^{2}, \mathrm{I}^{1} \text {, and/or } \mathrm{O}^{3} \text { in the same unit (ward, level etc.) } \\
\text { - Systematic steering of treatment beyond all SoFs } \\
\text { - Application of } \mathrm{SoF}^{4} \text { spanning roster and therapy plans }\end{array}$ & Rating scale $(0-2)$ \\
\hline & & - Number SoF${ }^{4}$-spanning sessions (meetings etc.) & Rating scale (1-3) \\
\hline III & $\begin{array}{l}\text { Continuity of treatment team } \\
\text { Implementation of team- and individual-related } \\
\text { continuity }\end{array}$ & $\begin{array}{l}\text { - Percentage of staff working in more than one } \mathrm{SoF}^{4} \text { (on a regular basis) } \\
\text { - Coordinated admission (coordinating staff member) } \\
\text { - Coordination of treatment by e.g. case manager, SoF} \mathrm{F}^{4} \text {-spanning care } \\
\text { - Home treatment by } I^{1} \text { - and } \mathrm{D}^{2} \text { - teams } \\
\text { - Outsourced PIA (outpatient department) team } \\
\text { (not working in } I^{1} \text { or } \mathrm{D}^{2} \text { ) }\end{array}$ & Rating scale (0-2) \\
\hline \multirow[t]{4}{*}{ IV } & \multirow[t]{4}{*}{$\begin{array}{l}\text { Multiprofessional Cooperation } \\
\text { Intense multiprofessional cooperation }\end{array}$} & $\begin{array}{l}\text { - Absolute number of mandatory sessions across all occupational } \\
\text { groups }\end{array}$ & Absolute number \\
\hline & & $\begin{array}{l}\text { - Measure/action to optimize cooperation across all occupational } \\
\text { groups }\end{array}$ & Rating scale $(0-1)$ \\
\hline & & • Training sessions multiprofessional cooperation & \\
\hline & & $\begin{array}{l}\text { - Number occupational groups working in home treatment } \\
\text { (on a regular basis) }\end{array}$ & Rating scale $(0-2)$ \\
\hline V & $\begin{array}{l}\text { Therapeutic group sessions across all settings } \\
\text { Therapeutic groups with members from all SoF }\end{array}$ & - Number of group sessions open for all SoFs ${ }^{4}$ & Rating scale $(0-2)$ \\
\hline \multirow[t]{2}{*}{$\mathrm{Vl}$} & \multirow{2}{*}{$\begin{array}{l}\text { Outreach home care } \\
\text { Multiprofessional treatment at home } \geq 1 \text { week }\end{array}$} & - Number CoT $T^{6}$ with home-treatment/ all I'-cases during $\mathrm{EP}^{5}$ & \\
\hline & & - Cars for home-visits & Rating scale (0-2) \\
\hline \multirow[t]{3}{*}{ VII } & \multirow[t]{3}{*}{$\begin{array}{l}\text { Involvement of informal caregivers } \\
\text { Informal caregivers as therapeutic tool }\end{array}$} & $\begin{array}{l}\text { - "Network" or other forms of systemic dialog with informal caregivers } \\
\text { and/or "carer-conference" and/or "caregiver groups" }\end{array}$ & Rating scale (0-1) \\
\hline & & - Number of groups open for informal caregivers & Rating scale $(0-1)$ \\
\hline & & $\begin{array}{l}\text { - Percentage of systemic training for staff/employees } \\
\text { (e.g. open dialogue) }\end{array}$ & Percentage \\
\hline \multirow[t]{2}{*}{ VIII } & \multirow[t]{2}{*}{$\begin{array}{l}\text { Accessibility of services } \\
\text { Geographical accessibility and accessibility of } \\
\text { teams }\end{array}$} & $\begin{array}{l}\text { - Accessibility of services within one-hour drive } \\
\text { - } 24 \text {-h-accessibility of multiprofessional mental health team } \\
\text { (not doctor on call or the like) } \\
\text { - Shuttle service for services users }\end{array}$ & Rating scale (0-2) \\
\hline & & - Waiting list & $\begin{array}{l}\text { Reverse rating scale } \\
(1-0)\end{array}$ \\
\hline IX & $\begin{array}{l}\text { Sovereign steering of services } \\
\text { Freedom of therapeutic decisions }\end{array}$ & $\begin{array}{l}\text { - Number of exeats } \geq 2 \text { nights in a row/all exeats during EP } \\
\text { - Number of exeats per service user/ calendar week during EP } \\
\text { - Daypatient treatment as well during the night } \\
\text { - Rules according to contract in all matters concerning setting } \\
\text { of treatment and length of treatment }\end{array}$ & Rating scale $(0-2)$ \\
\hline \multirow[t]{2}{*}{$x$} & \multirow[t]{2}{*}{$\begin{array}{l}\text { Cooperation across Sectors } \\
\text { Cooperation with ambulant care systems }\end{array}$} & $\begin{array}{l}\text { - Mutual scheduling and realizing of treatment with ambulant } \\
\text { care systems (SGB V) } \\
\text { - Mutual scheduling and realizing of treatment with social } \\
\text { welfare system (SGB XII) }\end{array}$ & Rating scale (0-2) \\
\hline & & • "Community psychiatric network" & Rating scale (0-1) \\
\hline \multirow[t]{2}{*}{$X I$} & \multirow[t]{2}{*}{$\begin{array}{l}\text { Expansion of professional expertise } \\
\text { Professionalisation of staff }\end{array}$} & $\begin{array}{l}\text { - Multiprofessional training of staff concerning FIT models } \\
\text { - Measures to multiply knowledge about FIT models } \\
\text { - FIT models as part of appraisal interviews }\end{array}$ & Rating scale (0-1) \\
\hline & & - Percentage of nurses/caregivers moderating group sessions & Percentage \\
\hline
\end{tabular}

NOTE: ${ }^{1} /$ inpatient, ${ }^{2} \mathrm{D}$ day-patient, ${ }^{3} \mathrm{O}$ outpatient, ${ }^{4} \mathrm{SoF}$ setting of treatment (outpatient, day-patient, inpatient), ${ }^{5} \mathrm{EP}$ evaluation period, ${ }^{6} \mathrm{CoT}$ case of treatment

\section{Validity and reliability}

The Grounded Theory approach required extensive face validation during the process of developing FIT64b specific components. Further, when presented to the steering committee, all components were found to be sufficiently practicable and extensive to describe FIT64b models. 
Table 2 Quantification of components by items collected from 12 departments

\begin{tabular}{lllll}
\hline \multirow{2}{*}{ Component } & \multicolumn{4}{l}{ Item characteristic } \\
\cline { 2 - 5 } & Mean & SD $^{1}$ & Min $^{2}$ & Max $^{2}$ \\
\hline II & 2.31 & 1.19 & 0 & 4 \\
III & 0.62 & 0.71 & 0 & 2 \\
V & 2.44 & 3.31 & 0 & 12 \\
VI & 2.13 & 0.93 & 1 & 4 \\
VII & 1.00 & 0.00 & 1 & 1 \\
VIII & 0.55 & 0.58 & 0 & 2 \\
IX & 0.65 & 0.48 & 0 & 1 \\
X & 0.67 & 0.48 & 0 & 1 \\
XI & 0.61 & 0.55 & 0 & 2 \\
Total & 0.88 & 0.53 & 0 & 2 \\
\hline
\end{tabular}

Note: ${ }^{1}$ SD standard deviation, ${ }^{2}$ Min; Max minimal and maximal value

When ten experts were interviewed, Lawshe's recommended cut-off content validity ratio of 0,62 was reached for each program component (Table 3).

The resulting Cronbach's alphas (Table 3) document a good reliability of eight program components and an excellent reliability for the total score.

The internal consistency of components I, V, and VI could not be evaluated, because of missing data for component I and only one item (i.e. no weighting) for components $\mathrm{V}$ and VI.

\section{Discussion}

\section{Main findings}

The declared objective of the recently implemented FIT64b models in Germany is the continuous resolution of highly institutionalised inpatient care, as had already been achieved in various health care systems worldwide by the implementation of community based, flexible, and integrative care models [25-29]. The German health care system entails its own legal and organisational logics [30]. Thus, internationally existing research on critical components, or fidelity and evaluative criteria of flexible and integrative forms of psychiatric care (FIT models), does not reflect the local situation. Consequently, 11 FIT64b program components were developed for describing the specific treatment structures and processes of German FIT64b models.

The identified FIT64b specific program components were: I transfer to outpatient setting; II flexible shift of settings; III continuity of treatment team; IV cooperation across all occupational groups; V therapeutic group sessions across all settings; VI outreach care; VII systematic inclusion of informal caregivers; VIII accessibility of services; IX sovereign steering of therapeutic decisions; $\mathrm{X}$ cooperation across sectors; XI expansion of professional expertise. Ten of eleven FIT components could be operationalised, quantified and united in the total score. All operationalised components showed sufficient content validity and eight components had a good reliability. The highest weights in the total FIT64b score had

Table 3 Psychometric properties and relative weights of program FIT components

\begin{tabular}{|c|c|c|c|c|c|c|c|c|c|c|c|c|}
\hline \multirow{2}{*}{ Measure } & & \multicolumn{11}{|c|}{ Program component } \\
\hline & & $C 2$ & C3 & C4 & C5 & C6 & $C 7$ & $\mathrm{C} 8$ & C9 & $\mathrm{C} 10$ & C11 & Total score \\
\hline \multicolumn{2}{|l|}{$\begin{array}{l}\text { Number of } \\
\text { related items }\end{array}$} & 4 & 5 & 4 & 1 & 1 & 3 & 4 & 4 & 3 & 4 & 33 \\
\hline \multirow[t]{2}{*}{$\begin{array}{l}\text { Item relevance } \\
\text { within } 1 \text { year }\end{array}$} & $M(S D)^{1}$ & $\begin{array}{l}3.38 \\
(1.21)\end{array}$ & $\begin{array}{l}3.60 \\
(1.18)\end{array}$ & $\begin{array}{l}3.40 \\
(1.03)\end{array}$ & $\begin{array}{l}3.60 \\
(1.17)\end{array}$ & $\begin{array}{l}4.10 \\
(0.57)\end{array}$ & $\begin{array}{l}3.70 \\
(0.99)\end{array}$ & $\begin{array}{l}3.78 \\
(1.00)\end{array}$ & $\begin{array}{l}4.05 \\
(0.99)\end{array}$ & $\begin{array}{l}3.50 \\
(0.73)\end{array}$ & $\begin{array}{l}3.55 \\
(0.90)\end{array}$ & $\begin{array}{l}3.63 \\
(1.03)\end{array}$ \\
\hline & Min; $\operatorname{Max}^{2}$ & $1 ; 5$ & $1 ; 5$ & $2 ; 5$ & $2 ; 5$ & $3 ; 5$ & $2 ; 5$ & $2 ; 5$ & $2 ; 5$ & $2 ; 5$ & $2 ; 5$ & $1 ; 5$ \\
\hline \multirow{2}{*}{$\begin{array}{l}\text { Certainty } \\
\text { about } \\
\text { this assessment }\end{array}$} & $M(S D)$ & $\begin{array}{l}3.65 \\
(0.89)\end{array}$ & $\begin{array}{l}3.68 \\
(0.91)\end{array}$ & $\begin{array}{l}3.70 \\
(0.95)\end{array}$ & $\begin{array}{l}4.00 \\
(0.47)\end{array}$ & $\begin{array}{l}3.63 \\
(1.27)\end{array}$ & $\begin{array}{l}3.63 \\
(1.27)\end{array}$ & $\begin{array}{l}3.63 \\
(1.00)\end{array}$ & $\begin{array}{l}3.83 \\
(1.13)\end{array}$ & $\begin{array}{l}3.77 \\
(0.63)\end{array}$ & $\begin{array}{l}3.85 \\
(1.21)\end{array}$ & $\begin{array}{l}3.47 \\
(0.97)\end{array}$ \\
\hline & Min; Max & $2 ; 5$ & $2 ; 5$ & $2 ; 5$ & $2 ; 5$ & $3 ; 5$ & $1 ; 5$ & $2 ; 5$ & $1 ; 5$ & $2 ; 5$ & $1 ; 5$ & $1 ; 5$ \\
\hline \multirow[t]{2}{*}{$\begin{array}{l}\text { Item relevance } \\
\text { within } 3 \text { year }\end{array}$} & $M(S D)$ & $\begin{array}{l}3.77 \\
(1.06)\end{array}$ & $\begin{array}{l}3.90 \\
(0.86)\end{array}$ & $\begin{array}{l}3.73 \\
(0.99)\end{array}$ & $\begin{array}{l}3.90 \\
(0.88)\end{array}$ & $\begin{array}{l}4.50 \\
(0.53)\end{array}$ & $\begin{array}{l}4.03 \\
(0.93)\end{array}$ & $\begin{array}{l}3.85 \\
(1.00)\end{array}$ & $\begin{array}{l}4.15 \\
(0.92)\end{array}$ & $\begin{array}{l}3.77 \\
(0.57)\end{array}$ & $\begin{array}{l}3.65 \\
(0.86)\end{array}$ & $\begin{array}{l}3.87 \\
(0.92)\end{array}$ \\
\hline & Min; Max & $1 ; 5$ & $2 ; 5$ & $2 ; 5$ & $3 ; 5$ & $4 ; 5$ & $2 ; 5$ & $2 ; 5$ & $2 ; 5$ & $2 ; 5$ & $2 ; 5$ & $1 ; 5$ \\
\hline \multirow{2}{*}{$\begin{array}{l}\text { Certainty } \\
\text { about } \\
\text { this assessment }\end{array}$} & $M(S D)$ & $\begin{array}{l}3.63 \\
(0.90)\end{array}$ & $\begin{array}{l}3.62 \\
(0.95)\end{array}$ & $\begin{array}{l}3.63 \\
(0.87)\end{array}$ & $\begin{array}{l}3.60 \\
(1.17)\end{array}$ & $\begin{array}{l}3.80 \\
(0.79)\end{array}$ & $\begin{array}{l}3.50 \\
(1.41)\end{array}$ & $\begin{array}{l}3.50 \\
(1.06)\end{array}$ & $\begin{array}{l}3.65 \\
(1.27)\end{array}$ & $\begin{array}{l}3.60 \\
(0.97)\end{array}$ & $\begin{array}{l}3.55 \\
(0.99)\end{array}$ & $\begin{array}{l}3.59 \\
(1.04)\end{array}$ \\
\hline & Min; Max & $2 ; 5$ & $2 ; 5$ & $1 ; 5$ & $1 ; 5$ & $2 ; 5$ & $1 ; 5$ & $1 ; 5$ & $1 ; 5$ & $1 ; 5$ & $1 ; 5$ & $1 ; 5$ \\
\hline \multicolumn{2}{|l|}{$\begin{array}{l}\text { Content validity } \\
\text { ratio (CVR) }\end{array}$} & 0.65 & 0.88 & 0.80 & 0.99 & 0.99 & 0.73 & 0.75 & 0.80 & 0.99 & 0.95 & 0.87 \\
\hline \multicolumn{2}{|l|}{ Cronbach's alpha } & 0.84 & 0.82 & 0.81 & n.a. ${ }^{3}$ & n.a. & 0.85 & 0.83 & 0.85 & 0.85 & 0.81 & 0.93 \\
\hline \multicolumn{2}{|c|}{$\begin{array}{l}\text { Relative weight of } \\
\text { each component (\%) }\end{array}$} & 11.21 & 16.03 & 12.20 & 2.99 & 4.73 & 10.63 & 12.10 & 6.35 & 10.87 & 12.89 & 100 \\
\hline
\end{tabular}

Note: ${ }^{1} M$ mean, SD standard deviation, ${ }^{2}$ Min; Max minimal and maximal value, ${ }^{3}$ n.a. not availabe 


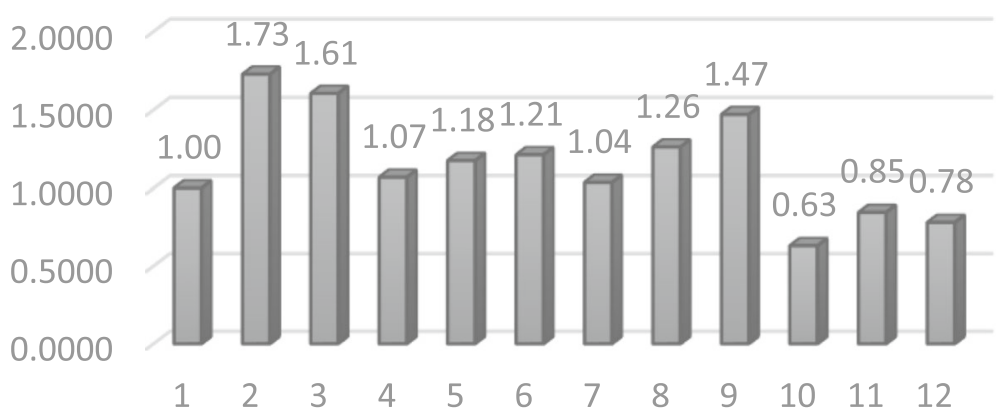

Fig. 3 Total score (weighted sum of component scores) for each of twelve participating department

components II, III, IV, VII, VIII, IX, X, XI. However, components V and VI could be operationalised by only one feature and had relatively low weights in the total FIT64b score.

\section{Strength and limitations}

This is the first English-language publication describing specific components of FIT models applicable to the German mental health care system. In several studies, focus groups and interviews were used to develop critical ingredients and evaluative criteria of international FIT models $[4,8,25,31-33]$. Most of them, however, used data from only service users or practitioners $[25,31]$. To our knowledge, only two publications collected data from all three stakeholder groups, i.e. from service users, carers, and practitioners [8, 33]. Yet, in our study, the response rates by carers were rather low, maybe due to the fact that carers are not sufficiently involved within FIT64b treatment models (von Peter, Ignatyev et al.: Evaluation of flexible and integrative treatment models in Germany - a mixed method, patient and staff-oriented, explorative study. (in progress)).

The identifying of program components was carried out using a GTM approach that enabled to combine an empirically based, open proceeding with a systematic and rule-based theory construction [20]. In contrast to methods, such as concept mapping or thematic analysis that are frequently used to develop evaluative or fidelity criteria e.g. [8], the method of GTM allows to develop a primarily praxis-based, both empirically and theoretically saturated, middle range theory by gradually building categories and relating them to each other [34]. A continued processing of the components is planed during a further study (von Peter, Ignatyev et al.: Evaluation of flexible and integrative treatment models in Germany - a mixed method, patient and staff-oriented, explorative study. (in progress)), aiming at differentiating them into core and peripheral ones $[3,25,35]$.

Further, our findings are limited by the unavailability of a standardised instrument for assessing and measuring
FIT64b components. The component "transfer to outpatient setting" could not be operationalised, and quantified because it was unclear if this component was a mediator or outcome itself. Testing internal consistency and content validity of all components were performed only using expert survey for pragmatic reasons. The expert panel was composed from academics of examined departments, which can lead to overestimating FIT64b components and be subject to biases. Furthermore, the present sample included only 12 mental health care departments which may limit the generalizability to other German FIT models.

\section{Comparison with the literature}

The 11 identified program components mostly comply with critical ingredients of international FIT models [4, $25,32,36,37]$, as they address the transformation processes from conventionally institutionalised towards flexible and integrated forms of psychiatric care. Critical ingredients of flexible and integrative care models vary due to local specifics of national health services. Involved within these variations are various factors, such as availability of resources, stage of program development, geographic location, and populations served [25]. Thus, compared internationally, our study revealed several similarities or distinctions concerning critical components of FIT models.

The key role of components "continuity of treatment team" and "flexible care management across settings" in German FIT64b is comparable with international FIT models [2]. These treatment approaches have a relatively long tradition in Germany as they are useful coordinating mechanisms in the situation of the highly fragmented national health care provision [38, 39].

The developing component "cooperation across sectors" can be also explained as a reaction to the decentralized, multi-layered German health care system [40]. Yet, in the attempt to empirically ground the latter component during our study, data achieved low saturation. This can be explained by the fact the underlying $\mathbb{\$ 6 4 b}$ 
legislation primary yields at integration of various forms of hospital care, but not beyond.

Component VI (outreach home care) had a relatively low statistical importance in our sample compared to other program components. This reflects that outreach care in Germany is little developed. In contrast, various models of assertive and outreach treatment are integral parts of several international FIT models; overlapping criteria can particularly be found for CRT and ACT treatment models, and, for example in the US the development of home treatment was political motivated as a reaction to the anti-psychiatric movement and two waves of deinstitutionalization [41]. On the other hand, all experts agreed that this component should be strongly developed in the future through the FIT64b-programmes and that its availability represents a good indicator for the quality of FIT-programs.

The developing components "inclusion of informal caregivers" and "accessibility of services" could be compensatory mechanisms to close the gap [40]. They are consistent with existent literature $[8,25,31-33]$. The components "multiprofessional cooperation" and "expansion of professional expertise" are in the actual trend with modern German medical education system [42].

\section{Conclusions}

The described program components are a first step in the process of operationally defining German FIT64b models.

Regarding scientific interests, the components allow for an integrated process of collecting, analysing, interpreting, and representing both qualitative and quantitative sets of data. They, thus, may help to overcome widely acknowledged challenges of mixed method designs in health services research $[43,44]$. By this way, they may serve as a theoretical basis for constructing fidelity tools and research guides to enable process and outcome evaluation of German FIT models.

Further, the specific FIT components identified may be useful for the implementation of German FIT64b models. They can serve as a target figure for the implementation and/or monitoring of FIT64b projects. By helping to bear in mind the different treatment components, they pave the way for purposive strategies of establishing or developing German FIT models.

\footnotetext{
Abbreviations

ACT: Assertive Community Treatment; Core CRT fidelity scale: Core Crisis Resolution Team fidelity scale; CRT: Crisis Resolution Teams;

DACTS: Dartmouth Assertive Community Treatment Scale; EvaMod64b: Evaluation of Models according to SGB §64b; FIT: Flexible and integrative treatment models; HT: Home Treatment; IF-ACT: Index of Fidelity for ACT; IPS25: Individual Placement and Support Fidelity Scale; TMACT: Tool for Measurement of $\mathrm{ACT}$
}

\section{Acknowledgements}

We wish to thank all the members of the research group who collected and analysed data during the research process: Sonja Indefrey, Burkhard Rehr, Manfred Zeipert, Onur Kankaya.

\section{Funding}

The authors received a financial grant from nine hospital government bodies interested in the evaluation of their own clinical projects for the research, authorship, and publication of this article: Psychosoziales Zentrum Itzehoe, Westklinikum Heide, Imland Klinik Rendsburg, Psychiatrische Klinik Lüneburg, Südharz Klinikum Nordhausen, Rudolf Virchow Klinikum Glauchau, Vitos Klinik Riedstadt, Vivantes Klinikum Berlin-Kreuzberg, Vivantes Klinikum BerlinNeukölln, Immanuel Krankenhaus und Poliklinik Rüdersdorf.

The funding bodies were represented in the study's steering committee by their heads of psychiatric departments. The steering committee was in control of the study's budget. It supervised the development of the study design, but there was no influence on the collection, interpretation or representation of data.

\section{Availability of data and materials}

The datasets underlying the current study are not publicly available due to the used data protection declaration and the nature of qualitative interviews where individual participants could be possibly identified. Parts of the data set are available from the research group on reasonable request.

\section{Authors' contributions}

SVP and JJ drafted the manuscript. All others commented and contributed to successive drafts. SVP, MH and YI contributed to study design. $\mathrm{YI}$ and JT are mainly responsible for statistical analysis. SVP, MH, JT, YI and JJ

contributed to data collection and analysis. JS contributed to secondary data analysis. All authors read and approved the final manuscript.

Ethics approval and consent to participate

Ethical approval for this study was obtained from the Ethics Committee of Medical Chamber Brandenburg (2016, No. S 7 (a)).

Informed, written consent was obtained in advance from all study participants.

Consent for publication

Not applicable.

\section{Competing interests}

The authors declare that they have no competing interests.

\section{Publisher's Note}

Springer Nature remains neutral with regard to jurisdictional claims in published maps and institutional affiliations.

\section{Author details}

'Department of Psychiatry and Psychotherapy, Charité University Medicine Berlin, Charitéplatz 1, 10117 Berlin, Germany. ${ }^{2}$ Brandenburg Medical School Theodor Fontane, Department of Psychiatry and Psychotherapy, Immanuel Klinik Rüdersdorf, Rüdersdorf bei Berlin, Germany. ${ }^{3}$ Biometry Section, Competence Center for Clinical Trials, University of Bremen, Bremen, Germany.

Received: 19 February 2018 Accepted: 23 August 2018

Published online: 03 September 2018

\section{References}

1. Thornicroft G, Tansella M. Components of a modern mental health service: a pragmatic balance of community and hospital care. Overview of systematic evidence Br J Psychiatry. 2004;185:283-90.

2. Ziguras S, Stuart G. A meta-analysis of the effectiveness of mental health case management over 20 years. Psychiatr Serv. 2000;51:1410-21.

3. Bond GR, Evans L, Kim H. Measurement of fidelity in psychiatric rehabilitation. Ment Health Serv Res. 2000;2:75-87.

4. Monroe-DeVita M, Teague GB, Moser LL. The TMACT: a new tool for measuring Fidelity to assertive community treatment. J Am Psychiatr Nurses Assoc. 2011;17:17-29. 
5. McHugo G, Drake R, Rapp C. Fidelity outcomes in the National Implementing Evidence-Based Practices Project. Psychiatr Serv. 2007;58: 1279-84.

6. Bond G, Peterson A, Drake R. Validating the revised individual placement and support Fidelity scale (IPS-25). Psychiatr Serv. 2012;63:758-63.

7. McGrew JH, Bond G, Salyers M. Measuring the fidelity of implementation of a mental health program model. J Consult Clin Psychol. 1994;62:670-8.

8. Lloyd-Evans B, Bond GR, Ruud T, Ivanecka A, Gray R, Osborn D, et al. Development of a measure of model fidelity for mental health crisis resolution teams. BMC Psychiatry. 2016;16:427

9. Stein LI, Test M. Alternative to mental hospital treatment: I. Conceptual model, treatment program, and clinical evaluation. Arch Gen Psychiatry. 1980;37:392-7.

10. Salize H, Rössler W, Becker T. Mental health care in Germany: current state and trends. Eur Arch Psychiatry Clin Neurosci. 2007;257:92-103.

11. Gijswijt-Hofstra M, Oosterhuis H, Vijselaar J, Freeman H. Psychiatric cultures compared: psychiatry and mental health Care in the Twentieth Century: comparisons and approaches. Amsterdam: University Press; 2005.

12. Caldas Almeida J, Mateus P, Tomé G. Joint action on mental health and well-being. Towards community-based and socially inclusive mental health care. 2016.

13. Deister A, Wilms B. Regionale Verantwortung übernehmen: Modellprojekte in Psychiatrie und Psychotherapie nach §64b SGB V. 1st edition; Köln: Psychiatrie Verlag; 2014.

14. König H-H, Heinrich S, Heider D, Deister A, Zeichner D, Birker T, et al. The regional psychiatry budget (RPB): a model for a new payment system of hospital based mental health care services? Psychiatr Prax. 2010;37:34-42.

15. Coleman M, Schnapp W, Hurwitz D, Hedberg S, Cabral L, Laszlo A, et al. Overview of publicly funded managed behavioral health care. Adm Policy Ment Health Ment Health Serv Res. 2005;32:321-40.

16. Schmid P, Steinert T, Borbé R. Implementing models of cross-sectoral mental health care (integrated health care, regional psychiatry budget) in Germany: systematic literature review. Psychiatr Prax. 2013:40:414-24.

17. Craig P, Petticrew M, Dieppe P. Developing and evaluating complex interventions: the new Medical Research Council guidance. BMJ. 2008;337: a1655

18. Krüger RA, Casey MA. Focus groups - a practical guide for applied research. 5th edition. Thousand Oaks: Sage Publications; 2015.

19. Mieg HA, Brunner B. Experteninterviews. Reflexionen zur Methodologie und Erhebungstechnik. Schweiz Z Für Soziol. 2004;30:199-222.

20. Strauss A, Corbin J. Grounded theory methodology. In: Handbook of qualitative research. Thousand Oaks: Sage Publications; 1994. p. 273-85.

21. von Peter S, Ignatyev Y, Indefrey S, Johne J, Schwarz J, Timm J, et al. Specific components for integrative and flexible care models according to $\S$ 64b SGB V. Nervenarzt 2017.

22. Lawshe $\mathrm{CH}$. A quantitative approach to content validity. Pers Psychol. 1975; 28:563-75.

23. Cronbach $\amalg$. Coefficient alpha and the internal structure of tests. Psychometrika. 1951;16:297-334.

24. Fayers P, Machin D. Quality of life: the assessment, analysis and interpretation of patient-reported outcomes, Second Edition. Chichester: John Wiley \& Sons; 2007.

25. McGrew JH, Bond GR. Critical ingredients of assertive community treatment: judgments of the experts. J Ment Health Adm. 1995:22:113-25

26. Tyrer P, Coid J, Simmonds S, Joseph P, Marriott S. Community mental health teams (CMHTs) for people with severe mental illnesses and disordered personality. Cochrane Database Syst Rev. 2007;3:CD000270.

27. Lloyd-Evans B, Paterson B, Onyett S, Brown E, Istead H, Gray R, et al. National implementation of a mental health service model: a survey of crisis resolution teams in England. Int J Ment Health Nurs. 2018;27:214-26.

28. Brimblecombe N. Community care and the development of intensive home treatment services. In: Acute mental health care in the community: intensive home treatment. Wiley; 2001.

29. Karlsson B, Borg M, Kim HS. From good intentions to real life: introducing crisis resolution teams in Norway. Nurs Inq. 2008;15:206-15.

30. Mueller-Stierlin AS, Helmbrecht MJ, Herder K, Prinz S, Rosenfeld N, Walendzik J, et al. Does one size really fits all? The effectiveness of a nondiagnosis-specific integrated mental health care program in Germany in a prospective, parallel-group controlled multi-Centre trial. BMC Psychiatry. 2017;17:283

31. McGrew JH, Wilson R, Bond GR. Client perspectives on helpful ingredients of assertive community treatment. Psychiatr Rehabil J. 1996;19:13-21.
32. Winter J, Calsyn R. The Darthmouth assertive community treatment scale (DACTS). A generalizability study. Eval Rev. 2000;24:319-38.

33. Morant N, Lloyd-Evans B, Lamb D, Kate Fullarton K, Eleanor Brown E, Beth Paterson $\mathrm{B}$, et al. Crisis resolution and home treatment: stakeholders' views on critical ingredients and implementation in England. BMC Psychiatry. 2017;17:254

34. Merton RK. Social theory and social structure. New York: Macmillan Publishing Co.; 1968.

35. Bond G, Williams J, Sharpe H, Leff S. Psychiatric Rehabilitation Fidelity Toolkit. 2000. https://www.hsri.org/publication/psychiatric_rehabilitation_ fidelity toolkit. Accessed 30 Jun 2018.

36. Stull L, McGrew JH, Salyers M. Processes underlying treatment success and failure in assertive community treatment. J Ment Health. 2012;21:49-56.

37. Munizza C, Gonella R, Tibaldi G. CMHC adherence to National Mental Health Plan standards in Italy: a survey 30 years after national reform law. Psychiatr Serv. 2011;62:1090-3.

38. Burns T, Rössler W, Malm U, Holloway F, Fioretti A. Case management and assertive community treatment in Europe. Psychiatr Serv. 2001;52:631-6.

39. Becker T, Hoffmann H, Puschner B, Weinmann S. Versorgungsmodelle in Psychiatrie und Psychotherapie. Stuttgart: W. Kohlhammer Verlag; 2008.

40. Bramesfeld A. How Community Oriented is Psychiatric Care in Germany? Psychiat Prax; 2003. p. 256-65.

41. Greenblatt M, Norman M. Deinstitutionalization: health consequences for the mentally ill. Annu Rev Public Health. 1983:4:131-54.

42. Konietzko R, Binder J, Frank L, Maudanz N. Interprofessional education in Erlangen: a needs analysis and the conceptual work of a student working group. GMS J Med Educ. 2016;33:Doc18

43. Creswell J, Plano Clark V. Designing and conducting mixed methods research. Thousand Oaks, CA: Sage; 2007.

44. Bazeley P. Editorial: integrating data analyses in mixed methods research. Mix Methods Res. 2009:3:203-7.
Ready to submit your research? Choose BMC and benefit from:

- fast, convenient online submission

- thorough peer review by experienced researchers in your field

- rapid publication on acceptance

- support for research data, including large and complex data types

- gold Open Access which fosters wider collaboration and increased citations

- maximum visibility for your research: over $100 \mathrm{M}$ website views per year

At BMC, research is always in progress.

Learn more biomedcentral.com/submissions 